\title{
Transmissão de Cargo
}

(Discurso do St. Wagner E. Campos)

O Ministro Wagner Estelita Campos transmitindo o cargo de Diretor-Geral do D.A.S.P. ao Prof. José Maria Arantes pronunciou o discurso que a seguir publicamos. Faz uma sintese de suas atividades no periodo difícil de sua gestão e exalta o alto gabarito da equipe de que dispõe o Departamento, ressaltando ainda a necessidade de restabelecer-se uma posição de cúpula do Serviço Público Federal, a "carreira de Técnico de Administração - espinhâ dorsal do D.A.S.P." (NOTA DA REDAÇÃO).

$\mathrm{E}$

Is o seu discurso:

A 11 de maio do corrente ano assumi a direção geral do D.A.S.P. em condições particularmente dificeis: com a saúde abalada, consciente dos problemas agudos que teria de enfrentar, alguns dêles de caráter urgente mas, acima de tudo, vendo-me na contingência de tomar a responsabilidade da direção de um órgão então desprestigiado, não por culpa de seus dirigentes e servidores, mas como decorrência de um conjunto de circunstâncias, nelas avultando o precário e às vêzes mesmo inexistente apoio que êste Departamento vinha merecendo de Governos anteriores e o aviltamento dos niveis da carreira de Técnico de Administração - a espinha dorsal do D.A.S.P. Não destaco nem mesmo refiro nesta rápida enumeração o caráter inevitàvelmente impopular das atividades de um órgão cuja missão é, por natureza, restritiva e disciplinadora.

Tôdas essas circunstâncias expu-las, com franqueza, ao Senhor Presidente da República, no primeiro contato que tive com Sua Excelência, como Diretor-Geral. Sua Excelência, com a visão segura que possui dos problemas administrativos, fêz então a promessa, exemplarmente cumprida, de integral apoio às atividades do D.A.S.P. Restabeleceu-se o indispensável despacho semanal do Diretor-Geral com o Senhor Presidente, o Diretor-Geral passou também a entender-se diretamente com os Ministros de 
Estado e dirigentes do mesmo nivel hierárquico e as atividades do D.A.S.P. mereceram inteiro prestigio da autoridade presidencial.

Êste o principal motivo, Senhor Diretor-Geral Prof. José Maria Arantes, por que lhe entrego hoje um D.A.S.P. recuperado em seu prestígio, discutido como sempre, vitima da injustiça de uns, objeto da compreensão de outros, mas respeitado por todos. E o que é mais importante, com respeitável bagagem de realizações em tão limitado periodo de poucos meses. Por outro lado, a carreira de Técnico de Administração já se acha incluida, como comêço de sua recuperação, nos degraus iniciais dos niveis universitários.

É de justiça destacar, entretanto, que o apoio presidencial, indispensável e prioritário, não foi o único fator de êxito: deve - D.A.S.P. também, em grande escala, a situação que hoje desfruta à competência e espirito público de uma brilhante equipe de dirigentes, ocupantes de cargos em comissão e funções gratificadas, e à inescedivel dedicação de seus servidores, dos mais graduados aos mais modestos. Seguramente em tudo isso o fator de menor pêso foi a atuação do Diretor-Geral, que teve em todos os momentos, da parte de seus auxiliares e assessôres, tôda a colaboração de que necessitava, e da parte do Senhor Presidente da República, o honroso apoio de que foi alvo.

Não pretendo, Senhor Diretor-Geral, transformar êste pequeno discurso num relatório, o que destoaria das finalidades e do caráter ameno e festivo desta reunião, mas sempre assinalar, inclusive para documentar que procurei cumprir os compromissos assumidos por ocasião de minha posse, algumas das principais realizações e iniciativas dêste periodo de pouco mais de cinco meses.

Antes disso, entretanto, é oportuno acentuar que o problema de maior gravidade que o D.A.S.P. enfrentava em maio e ainda enfrenta hoje, embora em escala mais atenuada, é o do panorama de distorções e desigualdades na politica salarial. Vale transcrever, a respeito, trechos iniciais de um roteiro de trabalho que apresentei ao Senhor Presidente da República logo no início de minha gestão. Dizia o documento:

"O estabelecimento de uma politica salarial alicerçada em bases sólidas, justas e duradouras representa um dos problemas de maior relevância e, no momento, de maior repercussão em tôda a atividade governamental.

As distorções existentes, resultando, inclusive, numa subversão da hierarquia salarial sem precedentes em nosso histórico, significam fator de perturbação em tôda 
a administração de pessoal do Govêrno e constituem condição impeditiva, pelo seu alcance nas finanças do país, de um eficaz combate à inflação. Trata-se, de resto, de fenômeno verificado na área dos Três Podêres e em tôdas as esferas administrativas".

De fato, as distorções e até as iniqüidades do panorama salarial não apenas apresentava repercussões técnicas e financeiras senão que também, e até talvez pudéssemos mesmo dizer principalmente, um fator de profundas conseqüências psicológicas e morais na massa do funcionalismo, afetando de maneira marcante - moral dos grupos de trabalho.

Nossa primeira responsabilidade, no sentido da atenuação dêsse mal, foi solicitada quando do exame do anteprojeto de que afinal resultou a Lei $n^{\circ} 4.345$, de 1964 . Vale assinalar as circunstâncias acentuadamente ingratas com que tive de me aproximar do assunto: de um lado, a Comissão Interministerial incumbida do exame inicial do problema, já se encontrava em fase final de trabalhos e com um tabela de sua autoria divulgada na imprensa; de outro lado, o teto que o Senhor Ministro da Fazenda havia fixado para a Comissão Interministerial foi sensivelmente reduzida por S. Ex para orientação dos trabalhos do D.A.S.P., o que exigia, inevitàvelmente, um esfôrço maior de contenção. Além disso os titulares da Fazenda e do Planejamento, imbuídos dos mais louváveis propósitos, ainda se batiam por que a nova Tabela de vencimentos passasse a vigorar apenas no próximo ano, concedendo-se, no ano corrente um aumento de sòmente $100 \%$. Não foram poucos nem pequenos os esforços que o D.A.S.P. teve de desenvolver, colaborando com o trabalho desenvolvido pelo Relator da matéria no Congresso, o Deputado Paulo Sarazate, no sentido de que a referida Tabela passasse a vigorar desde $1^{\circ}$ de junho do corrente ano.

A Lei $n^{\circ} 4.345$, apresentando as falhas inevitáveis de todo trabalho elaborado nas circunstâncias em que o foi, significa, entretanto, um avanço muito grande em relação a diplomas semelhantes anteriores, tendo em vista as distorções que atentou e as irregularidades que deteve. Da iniciativa e da responsabilidade do D.A.S.P. foi a supressão de algumas vantagens que vinham sendo objeto de reiiterados abusos e desvirtuamentos e a conseqüente criação dos níveis 19 a 22, chamados universitários.

Decorrência da Lei $n^{\circ} 4.345$, a revisão dos quadros das autarquias proporcionou ao D.A.S.P. um de seus momentos mais difíceis, tais as irregularidades que cumpria corrigir. O clamor que então se levantou, inclusive em certos setores da imprensa, foi, entretanto, da responsabilidade principal de grupos privile- 
giados relativamente pequenos mas poderosos pela sua influência e pela sua esfera de relações. A tarefa gerou incompreensôes, até mesmo de elementos altamente responsáveis nos quadros governamentais. E' certo que a revisão não poderia ser feita ex abrupto sob pena de grandes repercussões nos quadros de algumas autarquias e que, por outro lado, não se poderia retardar a concessão do aumento com tanta ansiedade aguardado por numeroso grupo de servidores. Por isso mesmo, tivemos de transigir, não quanto aos principios fundamentais mas quanto ao tempo e aos processos de atingir-se uma solução corretiva. Registre-se, neste passo, a atitude de elevada compreensão com que se houve, relativamente ao problema, o Ministro Juarez Távora, pois precisamente na área do seu Ministério é que os casos mais agudos se apresentaram.

Outra tarefa de grande envergadura que solicitou nossos esforços foi a resultante do anteprojeto de que se originou a recente lei relativa aos vencimentos da Magistratura, Ministério Público e Serviço Jurídico da Administração direta e indireta da União.

A situação, nessa área, era a mais caótica possivel, bastando referir a tremenda disparidade dos cálculos que, na giria administrativa, passaram a constituir a chamada "bola de neve", de que resultavam os pagamentos de vencimentos e vantagens, acarretando desigualdades e ilegalidades flagrantes e subvertendo inteiramente a hierarquia. Esse quadro, aliás, foi descrito, em côres fortes mas realistas, no relatório da Comissão integrada pelos Senhores Procurador e Consultor Geral dạ República e Procurador Geral da Fazenda Nacional. A solução afinal dada, sem ser a ideal, atenuou, pelo menos, de muito as distorções existentes e colocou ordem onde a desordem era a regra.

Ainda no sentido de atenuar, já que impossivel corrigir, as distorções da politica salarial foi a iniciativa, do que o D.A.S.P. participou, da Emenda Constitucional chamada da isonomia ou da paridade estebelecendo uniformidade nos Planos de Classificação e Pagamento na área dos Podêres Executivo, Legislativo e Judiciário e nos diversos níveis federativos. E' assunto recentemente reformulado em Mensagem remetida ao Congresso Nacional e que certamente merecerá cuidadosa atenção e patriótico exame de nossos legisladores. Na realidade, nada há que justifique as tremendas disparidades ora existentes na área dos Três Podêres e que poderão ser corrigidas, de futuro, resguardada a situação dos atuais funcionários.

Problema que mereceu nossa especial atenção foi o da tentativa de restabelecimento do sistema do mérito, que moraliza e democratiza o ingresso na função pública. Diversos fatôres vinham, ultimamente, perturbando e quase impossibilitando o fun- 
cionamento do sistema, dentre êles se destacando as diversas leis de efetivação de funcionários internos e a proliferação de cargos isolados de provimento efetivo. Os resultados, infelizmente, a êsse respeito, não surgiram na proporção de nossos ingentes esforços. Adotaram-se providências no sentido de abreviar o processamento da noção de concursados. Está em vias de produzir resultados êsse esfôrço na área da providência social, sendo de ressaltar, a propósito, a eficiente colaboração do Ministério do Trabalho. Ainda nesse setor importa registrar que o D.A.S.P. conseguiu levar a têrmo um Concurso que há 12 anos não se realizava: o de Agente Fiscal do Impôsto de Consumo, de grande interêsse para o Fisco. Realizou-se, também, o Concurso para Auxiliar de Coletoria, além de dezenas de outros para a administração direta e indireta. Demais disso, é importante ressaltar que a Lei $n^{\circ} 4.345$ reforçou a exigência do concurso público, estendendo-a aos cargos isolados.

Empenhou-se igualmente o D.A.S.P. em preservar a sua competência para a realização de Concursos nas autarquias e órgãos autônomos, competência que lhe foi atribuída pela Lei $n^{\circ} 3.780$, mas que vinha sendo ilidida em certos setores. Encontram-se em fase de realização os Concursos para Postalista e Agente Fiscal de Impostos Internos.

Nos setores de pessoal, cujos problemas foram, inegàvelmente, os que mais predominaram, pela sua natureza e pelo seu caráter urgente em minha gestão, desejo ainda destacar, sem comentários que seriam longos, as seguintes medidas, sem falar en diversas outras que também poderiam ser mencionadas: - Regulamento de acesso dos funcionários públicos civis do Poder Executivo - Decreto dispondo sôbre a revisão dos Quadros e Tabelas das autarquias federais, para efeito de aplicação do aumento pela Lei n? 4.345-64 - Regulamento da concessảo das Diárias de Brasilia - Classificação, nos niveis 19 a 22, dos cargos técnicos de nivel superior, ou equivalentes -- Normas, apro vadas em Decreto, para o regime de trabalho dos ocupantes dos cargos em comissão e de funções gratificadas. - Regulamentação do Regime de Tempo Integral - Normas, baixadas em Decreto, destinadas a disciplinar o ingresso em cargos públicos e a nomeação de candidatos habilitados em concurso. - Normas para a concessão de gratificação pela representação de Gabinete. Normas para a concessão de "jetton" de presença em órgãos de deliberação coletiva - Adoção do Horário único em Brasilia.

No setor de orçamento e organização há que destacar, antes de mais nada, a reformulação do Orçamento Geral da União cm consequiência da Lei $n^{\circ} 4.320$, de 1964 , que estatuiu normas gerais de Direito Financeiro para elaboração e contrôle dos orçamentos 
e balanços da União, dos Estados e Municípios e do Distrito Federal.

Medida de grande alcance foi o decreto que dispôs sôbre a elaboração orçamentária das entidades autárquicas e paraestatais da União com o objetivo de, em cumprimento da Lei, disciplinar e uniformizar matéria de importância fundamental para a vida financeira da União.

Uutro decreto instituiu, em Brasilia, os órgãos de planeja mento e execução das transferências de repartições públicas e da construção, reconstrução, restauração e reforma de unidades residenciais e de edifícios públicos.

Propôs ainda o D.A.S.P. ao Senhor Presidente da República medida visando a criação de um órgão que centralize, discipline e fiscalize a aplicação dos Auxílios e Subvenções concedidas no orçamento da União.

Deixo, em fase final de redação, um anteprojeto que poderá ser submetido já na próxima semana ao Senhor Presidente da República, no sentido de criar os órgãos destinados à Consolidação definitiva de Brasilia. Cogita-se, para isso, da criação do Conselho de Consolidação de Brasilia, de reaparelhamento do G.T.B. e da instituição de um Fundo Rotativo.

Já é tempo, realmente, de institucionalizar devidamente ä atividades relativas à Consolidação de Brasilia, tarefa estreitamente ligada à da Reforma Administrativa .

Menção especial deve merecer, neste rápido esbôço de nossas atividades, a iniciativa, aprovada pelo Senhor Presidente da República, da realização de censo do funcionalismo federal e autárquico, medida básica a adotar para chegar-se ao conhecimento correto de dados imprescindiveis à imperiosa revisão do sistema de classificação de cargos, à elaboração dos quadros definitivos de pessoal, à revisão da classificaçăo de cargos, à lotaçáo numérica e nominal das repartições e a outras informações da mesma natureza.

Permito-me também referir, de passagem, à colaboração dada pelo D.A.S.P. à instalação do Ministério do Planejamento.

Todo êsse esforrço, Senhor Diretor-Geral, notadamente o relativo aos setores de pessoal, custou-nos canseiras e sacrifícios. Exigiu-nos, principalmente, a fortaleza de espirito para enfrentar críticas sem fundamentos, incompreensões de tôda sorte e até mesmo apodos e injúrias. Nada disso nos entibiou o ânimo e a nossa única preocupação foi a de que se inquietaram, desnecessàriamente, dezenas de milhares de funcionários, com a intencional e maldosa divulgação de boatos sem fundamento, tais como os relativas à propalada demissão indiscriminada e em massa de interinos. 
Seja dito, aliás, que no fundo dêsses ataques sempre fờ possivel identififcar interêsses pessoais contrariados pelo conjunto de medidas moralizadoras que a Revolução não poderia deixar de lado.

Circunstância curiosa é a de que se procurou às vêzes, por ignorância ou má fé, descrever o D.A.S.P., como o algoz do funcionalismo.

Mas fàcilmente se esquece que o D.A.S.P., ao lado das providências de disciplina e contenção que de resto consultam aos mais legitimos interêsses do funcionalismo, toma iniciativas de cunho caracteristicamente liberal e humano, que passam, entre. tanto, quase sempre despercebidos.

Citarei alguns exemplos ilustrativos.

Resultou de parecer do Consultor-Jurídico do D.A.S.P., endossado pelo seu Diretor-Geral, posteriormente pelo ConsultorGeral da República e afinal aprovado pelo Senhor Presidente da República, a orientação liberal adotada inicialmente para apreciação das punições resultantes do Ato Institucional.

Igualmente do D.A.S.P. foi a iniciativa de submeter ao Senhor Presidente da República, projeto de lei que visa a amparar as familias dos funcionários punidos pela Revolıção de forma semelhante à que ocorre com os militares.

Resultou de esfôrço do D.A.S.P., em colaboração com a Consultoria Geral da República, a interpretação liberal dada ao art. $9^{\circ}$ da Lei $n^{\circ} 4.345$, no sentido da inclusão de diversas carreiras inclusive a de redator, nos níveis universitários.

Iniciativa igualmente do D.A.S.P. foi a da adoção do horáriu único em Brasilia, velha aspiração dos servidores que labutam na Capital Federal.

Finalmente, posso afirmar, solenemente, que não fôssem os: esforços do D.A.S.P. e a superior compreensão do Senhor Presidente da República, os servidores públicos civis da União sòmente teriam, até 31 de dezembro, um aumento de $100 \%$, ficando a vigência da nova Tabela retardada para o próximo ano.

\section{Senhor Diretor-Geral:}

Reune V. Ex: tôdas as credenciais para assegurar continuidade ao programa de atividades do D.A.S.P. Não lhe faltam, ao contrário lhe sobejam, os predicados morais e intelectuais para conduzir, em perfeita integração com os ideais revolucionários, a difícil, espinhosa, muitas vêzes incompreendida mas sempre necessária missão dêste órgão. Sua cultura geral, seu longo tirocínio de vida pública, sua intimidade com a doutrina e a prática da administração, sua capacidade de transıgência nos métodos e processos dentro da intransigência de principios, certamente per- 
mitirão que a sua gestão conduza a bom tèrmo o que iniciamos e corrija o que acaso merecer correçáo.

Dois fatôres decisivos não lhe faltarão como a mim não faltaram: o apoio e a superior orientação do Presidente Castelo Branco, que de maneira tão segura, prudente e patriótica vem conduzindo os destinos do país; e a colaboraçâo da brilhante e excepcional equipe de dirigentes e assessôres do D.A.S.P., apoiada numa infra-estrutura de um funcionalismo exemplar em sua dedicação ao trabalho e eficiente no cumprimento de seus deveres. Enfrentará certamente V. Ex $x^{a}$ dificuldades e obstáculos, os maiores dos quais dizem respeito ao desaparelhamento do D.A.S.P., em têrmos quantitativos de pessoal e em têrmos absolutos de recursos materiais e financeiros.

As providências iniciais que pudemos tomar, no torvelinho dos problemas diários e absorventes, requerem continuidade e melhor solução.

E' preciso, inclusive, que a carreira de Técnico de Administração recupere, integralmente, a posição de cúpula no Serviço Público, de que gozava quando de sua criação em 1940.

V. Ex contará, repito, com uma excepcional equipe de dirigentes e executores, teimosa equipe que soube, com a melhor de suas virtudes, embora desfalcada numèricamente, assegurar moral elevada mesmo nos períodos mais tormentosos do D.A.S.P.

Permita, Senhor Diretor-Geral, que en registre aqui, finalmente, como um dever de consciência, os meus agradecimentos a todos os meus auxiliares, dos mais graduados aos mais modestos, lotados em rasília ou no Rio, aos diretores, chefes, assessôres, pessoal de meu Gabinete, pela inestimável colaboração que me deram, com tanto entusiasmo e espírito público.

Agradeço ainda a diversos setores do Congresso Nacional e da imprensa, sem cuja preciosa colaboração não poderíamos levar a bom têrmo nossos propósitos.

Agradeço, finalmente o desvanecedor apoio com que me honrou o Presidente Castelo Branco, grande lider, e que a mim, modesto autor de um livro sôbre Chefia, proporcionou ao vivo tantas e inesquecíveis lições de chefia e liderança.

Afasto-me, com saudade, da convivência diária dos companheiros do D.A.S.P. e do contato semanal com o Senhor Presidente da República.

Procurarei levar para o nôvo pôsto que me foi destinado as nobres e generosas inspirações que tive o privilégio de receber nesta Casa.

Que V. Exa, Senhor Professor José Maria Arantes, seja merecidamente feliz em todos os aspectos de sua gestão, que será certamente das mais brilhantes neste Departamento. 